\title{
Determination of Bestation and p-Hydroxybestatin in Mouse Muscle and Serum after Oral Administration by High-Performance Liquid Chromatography with Fluorescence Detection
}

\author{
Junichi Ishida, Masaaki Kai and Yosuke Ohkura \\ Faculty of Pharmaceutical Sciences, Kyushu University 62, \\ Maidashi, Higashi-ku, Fukuoka 812 Japan
}

Key words : bestatin, p-hydroxybestatin, mouse, muscle, serum, distribution, high-performance liquid chromatography, fluorescence detection

\begin{abstract}
Summary
Microanalyses of bestatin and p-hydroxybestatin, possible therapeutic drugs for muscular dystrophy, in mouse muscle and serum have been accomplished by high-performance liquid chromatography with fluorescence detection. The drugs are extracted into dilute acetic acid for bestatin and perchloric acid for p-hydroxybestatin. The extracts are converted to fluorescent derivatives by means of the previously reported techniques, and the derivatives are separated on a reversed-phase column (TSK gel ODS-120T) with isocratic elution, respectively. The methods permit the quantification of bestatin and p-hydroxybestatin at concentrations of as low as $900 \mathrm{ng}$ and $130 \mathrm{ng}$ per $\mathrm{g}$ in mouse muscle, and $200 \mathrm{ng}$ and $30 \mathrm{ng}$ per $\mathrm{m} l$ in mouse serum, respectively. It was found that, in oral administration in the same doses $(50 \mathrm{mg} / \mathrm{kg}$ each), bestatin is distributed at higher concentrations to the muscle than p-hydroxybestatin, though the concentrations of the drugs are almost equal in the serum.
\end{abstract}




\section{Introduction}

Bestatin, [(2S, 3R)-3-amino-2-hydroxy-4-phenylbutanoyl-S-leucine] is a strong inhibitor of aminopeptidase B and leucine aminopeptidase, and enhances delayed-type hypersensitivity ${ }^{1 \sim 3)}$. Bestatin has been studied as a possible therapeutic drug for muscular dystrophy, cancer and resistant infections ${ }^{4)}$. On the other hand, p-hydroxybestatin, [(2S, 3R)-3-amino-2-hydroxy-4-(p-hydroxyphenyl)-butanoyl-S-leucine], is a major active metabolite of bestatin and has about 5-10 times stronger activity than bestatin in inhibiting aminopeptidase $\mathrm{B}^{5)}$. Therefore, the effect of bestatin in vivo may partly be ascribed to p-hydroxybestatin ${ }^{5}$. For the investigations of the therapeutic efficacy of bestatin and $\mathrm{p}$ hydroxybestatin on muscular dystrophy, it is important to examine whether those drugs can enter into muscle. However, bestatin and $\mathrm{p}$-hydroxybestatin distributed to muscle after administration of the drugs have not been measured.

We previously reported the methods ${ }^{6,7)}$ for the determination of bestatin and $\mathrm{p}$ hydroxybestatin in human serum by reversed-phase high-performance liquid chromatography (HPLC) with pre-column fluorescence derivatization, based on that bestatin is oxidized to phenylacetoaldehyde with periodate, which is converted to a fluorescent compound with 1,2-diamino-4,5-dimethoxybenzene ${ }^{8,9}$ (DDB), a fluorogenic reagent for aromatic aldehydes and that $\mathrm{p}$-hydroxybestatin is derivatized to a fluorescent derivative with DDB after formylation by Reimer-Tiemann reaction ${ }^{10}$.

This paper aims to apply the above two HPLC methods to the sensitive determinations of bestatin and p-hydroxybestatin in muscle and serum from mice dosed with bestatin or p-hydroxybestatin, and to investigate muscle and serum levels of the drugs after oral administration.

\section{Experimental}

\section{Chemicals and solutions}

Deionized and distilled water was used. Bestatin and p-hydroxybestatin were supplied from the Institute of Microbial Chemistry (Tokyo, Japan). DDB monohydrochloride was obtained from Dojindo Laboratories (Kumamoto, Japan). The resgent solutions used for the fluorescence derivatization were prepared as described previously ${ }^{6,7)}$.

\section{Apparatus and HPLC conditions}

The HPLC system consisted of a Toyo Soda $803 \mathrm{D}$ high-performance liquid chromatograph equipped with a Rheodyne 7125 syringe-loading sample injector valve $(100-\mu l$ loop) and a Shimadzu RF 530 fluorescence spectorometer fitted with a 12- $\mu l$ flow-cell. Emission and excitation wavelengths were 390 and $320 \mathrm{~nm}$ for the determination of bestatin, 425 and $345 \mathrm{~nm}$ for that of p-hydroxybestatin, respectively. The column was a TSK gel ODS-120 T (particle size, $5 \mu \mathrm{m}$; $150 \times 4 \mathrm{~mm}$ I.D.; Toyo Soda, Tokyo, Japan). This column could be used for more than 1000 injections with only a small decrease in the theoretical plate number. The flow-rate was $0.8 \mathrm{ml} / \mathrm{min}$. The column temperature was ambient (approximately $25^{\circ} \mathrm{C}$ ). The mobile phase for bestatin analysis was a mixture of $0.1 \mathrm{M}$ Tris $\cdot$ hydrochloric acid buffer $(\mathrm{pH} \mathrm{8.7)}$ and acetonitrile $(3: 1, \mathrm{v} / \mathrm{v})$, and that for $\mathrm{p}$ hydroxybestatin was a mixture of $50 \mathrm{mM}$ acetate hydrochloric acid buffer ( $\mathrm{pH} 2.2)$ and 
acetonitorile $(41: 9, \mathrm{v} / \mathrm{v})$.

\section{Administration of bestatin and p-hydroxybestatin, and sample preparation}

Inbred mice (C $57 \mathrm{BL}$, five weeks old, weight $17.5 \pm 1.6 \mathrm{~g}$ ) were used. The mouse received $50 \mathrm{mg} / \mathrm{kg}$ oral single dose of bestatin or $\mathrm{p}$-hydroxybestatin dissolved in saline by using a conductor needle. The administration was performed ca. $15 \mathrm{~min}$ after feeding. Then, only water was given to the mouse until sample preparation. The mouse was killed by exsanguination from a carotid artery. Trapezious muscle of the mouse was quickly taken, sliced, washed with saline and weighed after removing the saline with filter paper. The sliced muscle $(0.1 \mathrm{~g})$ was homogenized with a mixture of $150 \mu \mathrm{l}$ each of $8.4 \mathrm{mM}$ acetic acid and water, and then centrifuged at $10,000 \mathrm{~g}$ for $20 \mathrm{~min}$ at $0-2^{\circ} \mathrm{C}$. The supernatant was used for the determination. The blood was collected in a centrifuged tube and serum was separated.

\section{Procedure for the determination of bestatin}

A $15-\mu l$ portion of the supernatant from muscle homogenate or of serum was mixed with $15 \mu l$ of water and $150 \mu l$ of $4.2 \mathrm{mM}$ acetic acid. The mixture was heated for $5 \mathrm{~min}$ in a boiling water-bath and centrifuged at $800 \mathrm{~g}$ for $5 \mathrm{~min}$. To $100 \mu l$ of the supernatant were added $50 \mu l$ of $1.5 \mathrm{M}$ ammonium hydroxide and $25 \mu l$ of $3 \mathrm{mM}$ sodium periodate, and the mixture was allowed to atand at room temperature (approximately $25^{\circ} \mathrm{C}$ ) for 20 min. The excess periodate was decomposed by the addition of $25 \mu l$ of $12 \mathrm{mM}$ sodium sulphite. To the mixture, $200 \mu \mathrm{l}$ of $1.3 \mathrm{mM}$ DDB in $0.3 \mathrm{M}$ hydrochloric acid were added and the mixture was warmed at $37^{\circ} \mathrm{C}$ for $50 \mathrm{~min}$; then, $50 \mu l$ of $1.0 \mathrm{M}$ sodium hydroxide was added. A $100-\mu l$ volume of the final mixture was injected into the chromatograph. The amounts of bestatin in muscle and serum were calibrated by means of the standard addition method; $150 \mu l$ of water added to the muscle and $15 \mu l$ of water added to the serum in the procedure were replaced by $150 \mu l$ of a standard solution of bestatin for muscle $(2$ or $5 \mu \mathrm{g} / \mathrm{ml}$ ) and $15 \mu l$ of a standard solution of bestatin for serum ( 2 or $5 \mu \mathrm{g}$ / $\mathrm{m} l)$.

\section{Procedure for the determination of p-hydroxybestatin}

A $50-\mu l$ portion of the supernatant from muscle homogenate or of serum was mixed with $50 \mu l$ of water and $200 \mu l$ of $1.5 \mathrm{M}$ perchloric acid. The mixture was centrifuged at $800 \mathrm{~g}$ for $5 \mathrm{~min}$. To $200 \mu \mathrm{l}$ of the supernatant, $200 \mu \mathrm{l}$ of $2.6 \mathrm{M}$ potassium hydroxide were added. The mixture was centrifuged at $800 \mathrm{~g}$ for $5 \mathrm{~min}$. The supernatant $(250 \mu l)$ was placed in a screw-capped vial $(45 \times 12 \mathrm{~mm}$ I.D.), to which was added a $100-\mu l$ portion of chloroform. The mixture was heated in a heating module (Pierce, Rockford, I.L, U.S.A.) at $70^{\circ} \mathrm{C}$ for $8 \mathrm{~min}$ to formylate p-hydroxybestatin, and then cooled in ice-water for ca. $1 \mathrm{~min}$. To the mixture, $50 \mu \mathrm{l}$ of $14.0 \mathrm{M}$ acetic acid, $300 \mu \mathrm{l}$ of the DDB solution and $50 \mu l$ of $1.0 \mathrm{mM}$ hydrogen peroxide were successively added with cooling in ice-water. The mixture was heated in the heating module at $70^{\circ} \mathrm{C}$ for $10 \mathrm{~min}$ to develop the fluorescence and then cooled. A $100-\mu l$ portion of the aqueous layer was injected into the chromatograph. The amounts of $\mathrm{p}$-hydroxybestatin in muscle and serum were calibrated by means of the standard addition method; $150 \mu l$ of water added to the muscle and $50 \mu l$ of water added to the serum in the procedure were replaced by $150 \mu l$ of a standard solution of p-hydroxybestatin for muscle $(0.5$ or $2 \mu \mathrm{g} / \mathrm{ml})$ and $50 \mu l$ of a standard solution 
of p-hydroxybestatin for serum $(0.5$ or $2 \mu \mathrm{g} / \mathrm{ml})$.

\section{Results and Discussion}

\section{Determination of bestatin and p-hydroxybestatin in mouse muscle and serum}

Fig. 1 shows typical chromatograms of bestatin in muscle and serum from a mouse dosed with bestatin. The fluorescent derivative of bestatin was detected at the retention time of $12.5 \mathrm{~min}$, and it was well separated from endogenous fluorescent compounds and the reagent blank. The derivatization and HPLC conditions are actually the same as those reported for bestatin in human serum ${ }^{6}$. The calibration curves for bestatin were linear up to the concentrations of $25 \mu \mathrm{g}$ per g muscle and $50 \mu \mathrm{g}$ per $\mathrm{m} l$ serum, respectively. The limits of detection were $900 \mathrm{ng}(2.9 \mathrm{nmol})$ per $\mathrm{g}$ muscle and $200 \mathrm{ng}(650 \mathrm{pmol})$ per $\mathrm{m} l$ serum, respectively, at a signal-to-noise ratio of 2 .

Typical chromatograms obtained with muscle and serum from a mouse administered p-hydroxybestatin are shown in Fig. 2. The retention time for the fluorescent derivative of p-hydroxybestatin was $15.0 \mathrm{~min}$ and no interfering peaks arose around p-hydroxybestatin peak. The derivatization and HPLC conditions are nearly the same as those for $\mathrm{p}$-hydroxybestatin in human serum ${ }^{\text {?) }}$. The calibration curves for $\mathrm{p}$-hydroxybestatin were linear up to the concentrations of $25 \mu \mathrm{g}$ per g muscle and $50 \mu \mathrm{g}$ per $\mathrm{m} l$ serum, respectively. The limits of detection were $130 \mathrm{ng}(400 \mathrm{pmol})$ per $\mathrm{g}$ muscle and $30 \mathrm{ng}(90 \mathrm{pmol})$ per $\mathrm{m} l$ serum, respectively.

The extraction of bestatin and p-hydroxybestatin from muscle was carried out by homogenizing the sample with $4.2 \mathrm{mM}$ acetic acid. The recoveries of bestatin $(5 \mu \mathrm{g} / \mathrm{g})$
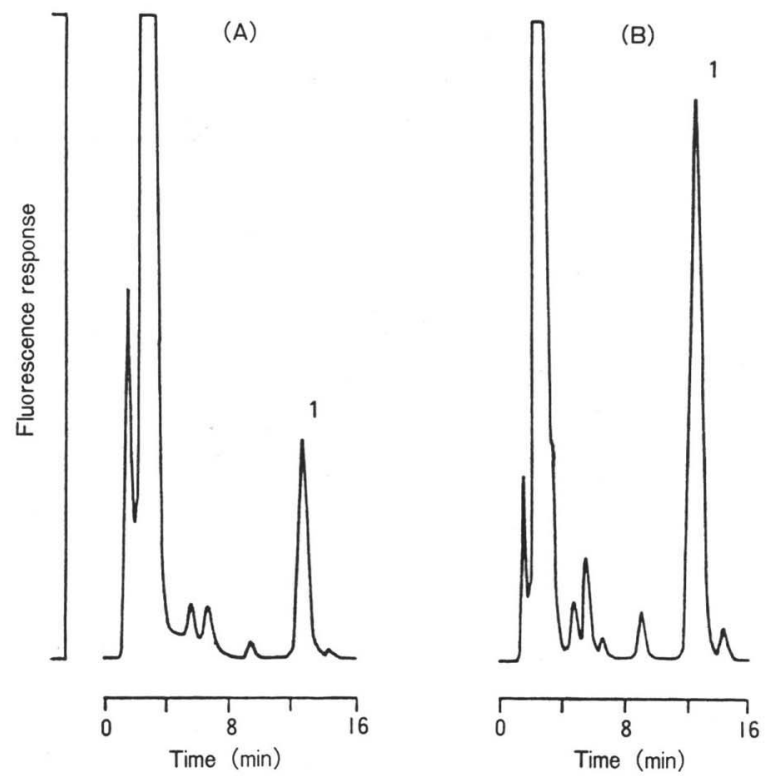

Fig. 1. Chromatograms of bestatin in (A) muscle and (B) serum at $1 \mathrm{~h}$ after oral administration of bsstatin to a mouse. Dose: $50 \mathrm{mg} / \mathrm{kg}$. Peaks: 1, bestatin; others, endogenous substances and reagent blank. Concentrations of bestatin: $\mathrm{A}, 5.70 \mu \mathrm{g} / \mathrm{g}$ in muscle; $\mathrm{B}, 7.52 \mu \mathrm{g} / \mathrm{ml}$ in serum. 

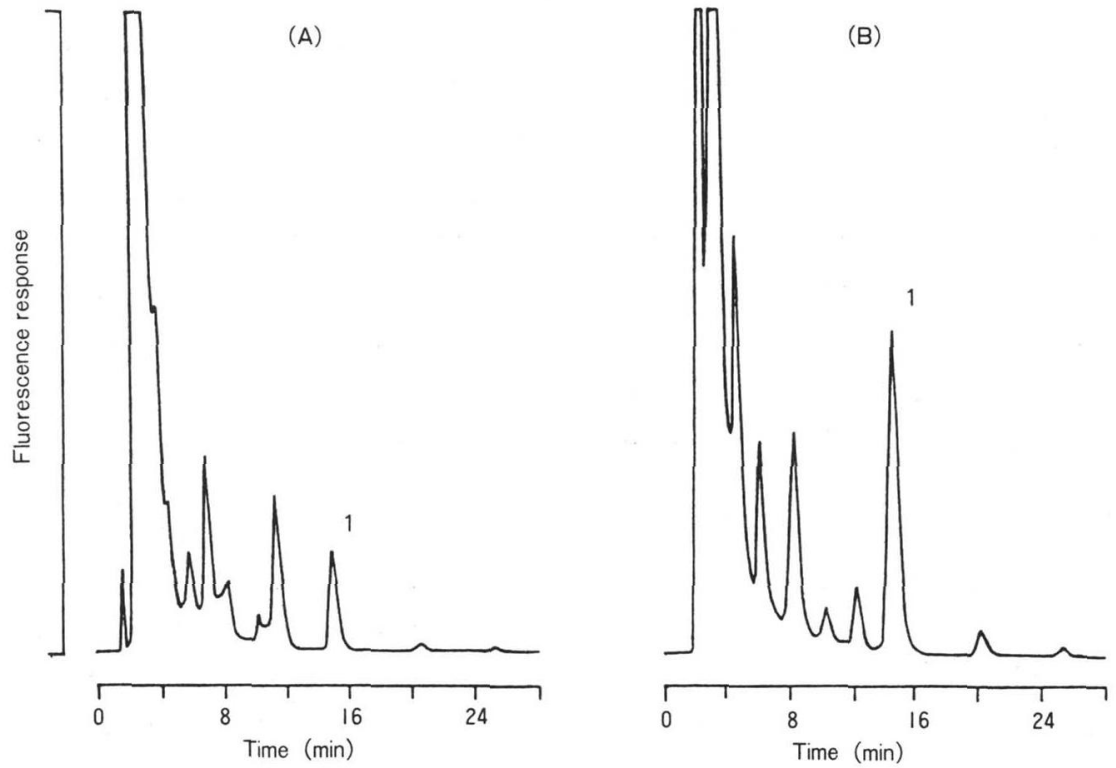

Fig. 2. Chromatograms of p-hydroxybestatin in (A) muscle and (B) serum at $1 \mathrm{~h}$ after oral administration of $\mathrm{p}$-hydroxybestatin to a mouse. Dose: $50 \mathrm{mg} / \mathrm{kg}$. Peaks: 1, phydroxybestatin; others, endogenous substances and reagent blank. Concentrations of p-hydroxybestatin: A, $3.08 \mu \mathrm{g} / \mathrm{g}$ in muscle; $\mathrm{B}, 6.30 \mu \mathrm{g} / \mathrm{m} l$ in serum.

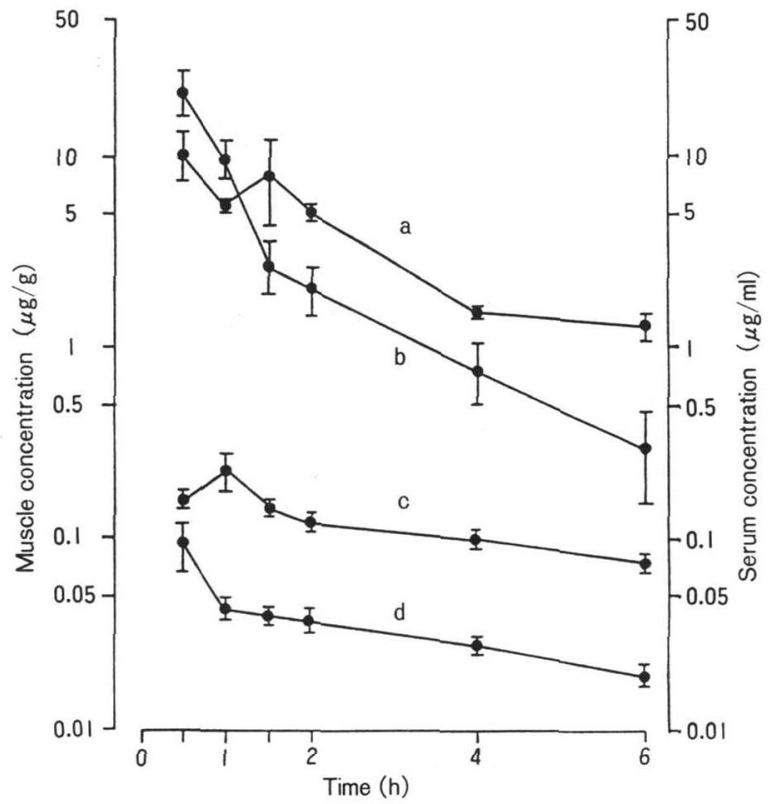

Fig. 3. Concentrations of bestatin and p-hydroxybestatin in mouse muscle and serum after oral administration $(50 \mathrm{mg} / \mathrm{kg}$ in single doses) of bestatin. Mean values of the concentrations obtained with three mice were plotted. Curves: a, bestatin in muscle; b, bestatin in serum; c, p-hydroxybestatin in muscle; d, p-hydroxybestatin in serum. 
and p-hydroxybestatin $(2 \mu \mathrm{g} / \mathrm{g})$ added to a drug-free muscle were $63.0 \pm 1.3$ and $62.2 \pm$ $1.0 \%$ (mean \pm S.D., $\mathrm{n}=5$ in each case), respectively. The use of ice-water, $1 \mathrm{M}$ perchloric acid or $50 \mathrm{mM}$ disodium carbonate in place of the acetic acid resulted in lower recoveries for both bestatin and p-hydroxybestatin; recoveries of 61 and $50 \%$ for ice-water, 59 and $55 \%$ for $1 \mathrm{M}$ perchloric acid, and 44 and $54 \%$ for $50 \mathrm{mM}$ disodium carbonate, respectively, were observed. On the other hand, bestatin and p-hydroxybestatin in serum were completely extracted by heating the sample with $3.5 \mathrm{mM}$ acetic acid and $1.0 \mathrm{M}$ perchloric acid, respectively; recoverieswere $96.0 \pm 1.8 \%$ for bestatin $(5 \mu \mathrm{g} / \mathrm{m} l)$ and $100.0 \pm 2.2 \%$ for $\mathrm{p}^{-}$ hydroxybestatin $(2 \mu \mathrm{g} / \mathrm{m} l)$ (mean \pm S.D., $\mathrm{n}=5$ in each case).

\section{Distribution of bestatin and p-hydroxybestatin in mouse muscle and serum}

Fig. 3 shows time-concentration curves obtained by the determination of bestatin and p-hydroxybestatin in mouse muscle and serum after oral administration $(50 \mathrm{mg} / \mathrm{kg})$ of bestatin. Muscle concentration of bestatin (Fig. 3, a) is about a half of the serum concentration (Fig. 3, b) at $0.5-1 \mathrm{~h}$, but is at least 1.5 times higher between 1.5 and $6 \mathrm{~h}$ after the administration. p-Hydroxybestatin resulted from bestatin was observed in both muscle and serum samples. The concentrations of $\mathrm{p}$-hydroxybestatin in muscle (Fig. 3, c) are higher than those in serum (Fig. 3, d). The bestatin and p-hydroxybestatin concentrations in muscle and serum after oral administration of bestatin seem to decrease biexponentially. Half-lives of bestatin and p-hydroxybestatin in muscle are 0.7 and $1.2 \mathrm{~h}$ for the former phase, and 7.6 and $3.9 \mathrm{~h}$ for the latter phase, respectively (Fig. 3, a and c). In the case of serum concentration, those of bestatin and p-hydroxybestatin are 0.3

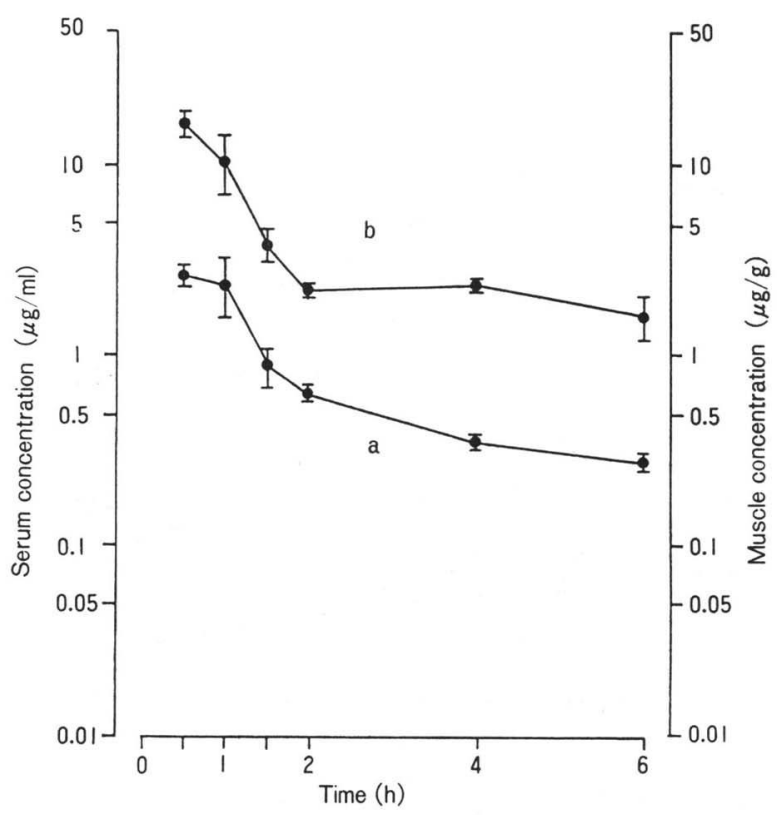

Fig. 4. Concentrations of p-hydroxybestatin in mouse muscle and serum after oral administration $(50 \mathrm{mg} / \mathrm{kg})$ of $\mathrm{p}$-hydroxybestatin. Mean values of the concentrations of $\mathrm{p}$-hydroxybestatin obtained with three mice were plotted. Curves: a, p-hydroxybestatin in muscle; b, phydroxybestatin in serum. 
and $0.5 \mathrm{~h}$ for the former phase, and 1.5 and $4.4 \mathrm{~h}$ for the latter phase, respectively (Fig. $3, \mathrm{~b}$ and $\mathrm{d}$ ).

Time-concentration curves of $\mathrm{p}$-hydroxybestatin in mouse muscle and serum after the oral administration in the same amount as for bestatin $(50 \mathrm{mg} / \mathrm{kg})$ are shown in Fig. 4. The muscle concentrations of p-hydroxybestatin (Fig. 4, a) are between $1 / 3-1 / 6$ of those in serum (Fig. 4, b), at all the periods after the administration. The p-hydroxybestatin concentrations in muscle and serum after the oral administration decrease biexponentially, with half-lives of $0.5 \mathrm{~h}$ for the former phase and $5.3 \mathrm{~h}$ for the latter phase in muscle (Fig. 4, a) and those of $0.5 \mathrm{~h}$ for the former phase and $3.6 \mathrm{~h}$ for the latter phase in serum (Fig. 4, b).

The muscle concentrations of bestatin in the case of bestatin administration (Fig. 3, a) are at least 1.5 times higher than those of p-hydroxybestatin in p-hydroxybestatin administration in the same amount as for bestatin (Fig. 4, a). On the other hand, the serum concentrations of bestatin (Fig. 3, b) are equal or slightly lower than those of $\mathrm{p}^{-}$ hydroxybestatin (Fig. 4, b). This suggests that bestatin distributes more readily into muscle cells than p-hydroxybestatin.

\section{Acknow ledgements}

We are grateful to Drs. H. Umezawa and T. Aoyagi, the Institute of Microbial Chemistry, for encouragement throughout this work. This work was partly supported by a Grant-in-Aid for New Drug Development Reserch from the Ministry of Health and Welfare, Japan. We are also grateful to Miss. S. Yonekura for her skillful assistance.

\section{References}

1) H. Umezawa, M. Ishizuka, T. Aoyagi and T.Takeuchi. Enhancement of delayed-type hypersensitivity by bestatin, an inhibitor of aminopeptidase B and leucine aminopeptidase. J. Antibiot. $24: 857-859$ (1976).

2) H. Umezawa, T. Aoyagi, H. Suda, M. Hamada and T. Takeuchi. Bestatin, an inhibitor of aminopeptidase B, produced by actinomycetes. J. Antibiot. 29 : 97-99 (1976).

3) H. Suda, T. Aoyagi, T. Takeuchi and H. Umezawa. Inhibition of aminopeptidase B and leucine aminopeptidase by bestatin and its stereoisomer. Arch. Biochem. Biophys. $177: 196-200$ (1976).

4) M. Ishizuka, T. Masuda, N. Kanbayashi, S. Fukasawa, T. Takeuchi, T. Aoyagi and H. Umezawa. Effect of bestatin on mouse immune system and experimental murine tumors. J. Antibiot. 33 : 642-652 (1980).

5) H. Umezawa (Editor). Small molecular immunomodifiers of microbial origin; Fundamental of clinical studies of bestatin, Pergamon, New York. p.8-9 (1981).

6) J. Ishida, M. Yamaguchi, M. Kai, Y. Ohkura and M. Nakamura. Determination of bestatin in serum by high-performance liquid chromatography with fluorescence detection. J. Chromatogr. $305: 381-389$ (1984).

7) J. Ishida, M. Kai and Y. Ohkura. Determination of p-hydroxybestatin in human serum by high-performance liquid chromatography using fluorescence detection. J. Chromatogr. $344: 267-$ 274 (1985).

8) M. Nakamura, M. Toda, H. Saito and Y. Ohkura. Fluorimetric determination of aromatic aldehydes with 4,5-dimethoxy-1,2-diaminobenzene. Anal. Chim. Acta. $134: 39-45$ (1982).

9) M. Nakamura, M. Toda, K. Mihashi, M. Yamaguchi and Y. Ohkura. Fluorescent product in the determination of aromatic aldehydes with 4,5-dimethoxy-1,2-diaminobenzene. Chem. Pharm. Bull. 31 : 2910-2912 (1983).

10) K. Reimer and F. Tiemann. Ueber die einwirkung von chloroform auf alkalische phenolate. Ber. 9 : 824-828 (1876). 